\title{
Recent advances in lipoproteins and atherosclerosis: A nutrigenomic approach
}

\author{
By Sergio López, Almudena Ortega, Lourdes Varela, Beatriz Bermúdez, Francisco JG Muriana \\ and Rocío Abia*
}

\author{
Grupo de Nutrición Celular y Molecular, Instituto de la Grasa, Consejo Superior de Investigaciones \\ Científicas, Avda. Padre García Tejero, 4, Sevilla 41012, España. \\ * Corresponding author: abia@ig.csic.es
}

\section{RESUMEN}

Nuevos avances sobre el efecto de las lipoproteínas en la aterosclerosis: Una aproximación nutrigenómica.

La aterosclerosis es una enfermedad en la que múltiples factores, entre los que se encuentra la dieta, contribuyen a la degradación de la pared vascular. En la etiología de la aterogénesis son determinantes las lipoproteínas plasmáticas y los distintos tipos celulares de la pared vascular, incluyendo una respuesta inflamatoria. La ingesta de alimentos afecta la concentración y composición de las lipoproteínas, ejerciendo un papel de riesgo o protector durante las diferentes etapas del proceso aterosclerótico. Es importante destacar que la naturaleza de las lipoproteínas y por lo tanto su papel en la enfermedad cardiovascular, también depende del tiempo transcurrido entre comidas. Por ejemplo, las lipoproteínas postprandiales ricas en triglicéridos, es decir aquellas que se originan inmediatamente después de la ingestión de una comida rica en grasas, poseen una gran influencia en la aterogénesis que hasta ahora solo se concedía a las lipoproteínas de baja densidad y en ayunas. Los recientes avances en tecnologías «ómicas» están ayudando a descifrar los complejos mecanismos celulares y moleculares de las lesiones ateroscleróticas originados en las distintas fases de la alimentación. En esta revisión se discuten los nuevos avances en la investigación sobre los efectos vasculares de lipoproteínas plasmáticas en estado de ayuno y postprandial, resaltando aquellos obtenidos con la tecnología de la nutrigenómica.

PALABRAS CLAVE: Aterosclerosis - Células vasculares - Dieta - Lipoproteínas - Periodo postprandial.

\section{SUMMARY}

Recent advances in lipoprotein and atherosclerosis: A nutrigenomic approach.

Atherosclerosis is a disease in which multiple factors contribute to the degeneration of the vascular wall. Many risk factors have been identified as having influence on the progression of atherosclerosis among them, the type of diet. Multifactorial interaction among lipoproteins, vascular wall cells, and inflammatory mediators has been recognised as the basis of atherogenesis. Dietary intake affects lipoprotein concentration and composition providing risk or protection at several stages of atherosclerosis. More intriguingly, it has been demonstrated that the extent to which each lipid or lipoprotein is associated with cardiovascular disease depends on the time to last meal; thus, postprandial lipoproteins, main lipoproteins in blood after a high-fat meal, have been shown to strongly influence atherogenesis. As a complex biological process, the full cellular and molecular characterization of atherosclerosis derived by diet, calls for application of the newly developing "omics" techniques of analysis. This review will considered recent studies using high-throughput technologies and a nutrigenomic approach to reveal the patho-physiological effects that the fasting and postprandial lipoproteins may exert on the vascular wall.

KEY-WORDS: Atherosclerosis - Diet - Lipoproteins Nutrigenomics - Postprandial state - Vascular cells.

\section{INTRODUCTION}

Since the human genoma DNA sequence was completed, nutrition research has undergone a shift from epidemiology to molecular biology and genetics. In that sense, the relationships between nutrient availability and adaptive changes in gene expression are critical to understanding the role of nutrition in health and disease. Unbalanced diets alter nutrient-gene interaction increasing the development of chronic disease. Nutrient modulation of gene expression serves to protect the cell from the deleterious effects of both undernutrition and over-nutrition. It is now well established that modifying the consumption of certain dietary compounds can prevent some monogenic diseases (a single dysfunctional gene is responsible for disease), such as galactosemia and phenylketonuria (van Spronsen et al., 2001; Thompson et al., 2003). In contrast, dietary interventions to prevent the onset of polygenic diseases such as cardiovascular disease (CVD), cancer, diabetes type II and obesity requires not only knowledge of how a single nutrient may affect a biological system but also how a mixture of nutrients will interact to modulate biological functions (Arab, 2004).

Atherosclerosis is a complex, multifactorial disease associated with accumulation of lipids in lesions along blood vessels, leading to the occlusion of blood flow, with oxidative and inflammatory components playing major roles in its cause. Environmental factors with particular emphasis on nutrition as well genetic factors appear to be responsible for these aberrant oxidative and inflammatory components and the lipid abnormalities associated with the disease. Diet may contribute to the atherosclerotic process 
by affecting lipoprotein concentration, their composition (Abia et al., 2001; Furtado et al., 2008) and degree of oxidation (Fitó et al., 2007). Much of the knowledge about the relationship between lipoprotein metabolism and the development of atherosclerosis is based on analysis in the fasting state reflecting endogenous metabolism, particularly; the focus has been on the role of low-density lipoprotein (LDL), and of oxidatively modified LDL (oxLDL) in the initiation and progression of this disease. Although the presence of oxLDL, in general, supports the oxidative hypothesis of atherogenesis, accumulating evidence indicates that it is mainly specific oxidized phospholipids on apoB-100 particles, and particularly on the $\mathrm{Lp}(\mathrm{a})$ fraction, that correlate with increased CVD risk (Tsimikas et al., 2006). Contrary to LDL, high-density lipoprotein (HDL) has several beneficial protective properties (Tall, 2008); however, remodelling of HDL due to chemical/physical modifications can dramatically affect its functions, leading to dysfunctional HDL that could promote atherogenesis (Hurtado et al., 1996, Valiyaveettil et al., 2008).

Over the years, univariate analyses have implicated triglycerides as a contributor of atherosclerosis. In two recent prospective studies, non-fasting plasma triglyceride levels have represented an independent cardiovascular risk factor to a greater extent than fasting levels (Bansal et al., 2007; Nordestgaard et al., 2007). Furthermore, a recent study (Mora et al., 2008) has demonstrated that HDL cholesterol, triglycerides, total/HDL cholesterol ratio, and apolipoprotein A-1 predict CVD when measured in the non-fasting state. This is in line with the fact that Western population spend most of the day in the postprandial state. Postprandial lipemia is characterized by a rise of triglyceride-rich lipoproteins (TRL) [chylomicrons, very-low density lipoproteins (VLDL) and their respective remnant particles] and small dense LDL particles after a rich fat meal. Postprandial lipid and lipoprotein metabolism is modulated by meal composition, several lifestyle conditions, physiological factors and pathological conditions (Lopez-Miranda et al., 2007). Remodelling of lipoproteins in this stage greatly out-number those occurring at fasting conditions, being food intake the main mechanism inducing these alterations. The magnitude of postprandial lipemia represents an important risk factor for the development of atherosclerosis and coronary artery disease (Cohn, 2006), it is therefore becoming increasingly evident that future efforts to study atherosclerosis should include the effects of postprandial lipoproteins.

Although certain key risk factors affecting atherosclerosis have been identified, the full molecular characterization will remain a challenge in the next century to come. As a complex biological process, the cellular and molecular details of the growth, progression and regression of the vascular lesions of atherosclerosis call for application of the newly developing "omics" techniques of analysis. Nutrigenomics is a study of interactions of dietary components with the genoma and the resulting changes in gene expression, structure, and function of proteins and other metabolites (Subbiah, 2008). Profiling gene expression using microarrays has proven useful in identifying new genes that may contribute to features of the atherosclerosis lesion (transcriptomics). Because a change in gene expression does not necessarily lead to measurable changes in plasma protein levels, profiling proteoma rather than mRNA, has became and complementary technique (proteomics). This review summarizes more recent studies, including these technologies, that have lead to the development of new hypothesis concerning the cellular response to lipoproteins and to identify the major cellular pathways responsive to them. Furthermore, we present data that support the role of TRL in the atherosclerosis process.

\section{FASTING LIPOPROTEIN CONTROL OF GENE AND PROTEIN EXPRESSION IN ATHEROSCLEROSIS}

LDL cholesterol is considered a major factor in atherosclerosis development. An increase in plasma LDL levels leads to an increase of entry of LDL into the intima of susceptible arteries. Depending on the degree of oxidation, oxLDL have been proposed to be involved in many atherogenic changes in the vascular wall such as, proliferation, migration, apoptosis and necrosis of vascular cells, furthermore, oxLDL itself induces oxidative stress in endothelial cells (EC), smooth muscle cells (SMC), and macrophages, resulting in atherogenic plaque formation (Galle et al., 2006). During an early stage of atherosclerosis, oxLDL is incorporated into macrophages via receptor-mediated endocytosis, leading to macrophage transformation into foam cells and thus the plaque formation of atherosclerotic lesions. As the lesion progresses, a necrotic core of lipid, oxidised lipids, and other cell debris accumulates. Increases in extracellular matrix production results in the formation of a fibrous cap or plaque that walls off the necrotic core from the endothelium. In time, increased lesion size and local proliferation of SMC can cause to protrude into the lumen. Weakening events can lead to plaque rupture, thrombosis, and myocardial infarction or stroke.

\subsection{Effect of lipoproteins on regulation of gene and protein expression in vascular endothelial cells}

It has been proposed that the biological effect of modified lipoproteins may be partly attributed to its effect on a shift of the pattern of gene expression in endothelial cells. Thus, the analysis of differential gene expression in the endothelium is critical to our understanding of the sequence of events leading to the formation of atherosclerotic lesion. This approach 
has been utilised by Virgili et al. (2003), to identify genes involved in atherogenesis in primary human umbilical vein endothelial cells (HUVEC) challenged with oxLDL. Treatment of HUVEC with oxLDL altered the expression of genes encoding for transcription factors (Gata binding protein 2, GATA-2; sterol regulatory element-binding protein 1, SREBP1 and SREBP2), cell receptors (Tromboxane $A_{2}$ receptor, TXA2R), adhesion molecules (vinculin, cell-surface glycoprotein MUC18), extracellular matrix proteins (matrix metalloproteinase 2, MMP2; MMP9), and enzymes involved in cholesterol metabolism that compose a "response to injury" type of effect. OxLDL could induce alterations in the signalling pathways mediated by platelet derived factor receptor (PDGFR) and farnesyl transferase (FTase), which could in turn lead to metabolic dysfunction in the endothelium.

Phospholipid oxidation products of 1-palmitoyl-2arachidodonyl-sn-glycero-3-phosphorylcholine (PAPC) present in midly oxLDL activate EC leading to enhance monocyte/EC interaction (Berliner et al., 2001). Oxidised phospholipids in human plasma associated with apo(a) have shown to be predictive of the presence and progression of atherosclerosis (Tsimikas et al., 2005). Genes and global pathways involved in the inflammatory effects of oxPAP have been described by Gargalovic et al. (2006), by examining human aortic EC (HAEC) cultures derived from multiple heart transplant donors. The approach was based on the fact that a natural population will exhibit multiple genetic or epigenetic variations that perturb the expression of individual genes, as well as entire pathways. These variations could be quantitated by expression array profiling and analysed by using system biology approaches. Expression arrays yielded 1,043 differentially expressed genes, some of these genes including interleukin 8 (IL-8), heme oxygenase 1 (HMOX1) and members of the SREBP pathway, have previously been shown to be regulated by oxPAPC, but the majority represented novel oxPAPC targets (see Gargalovic et al., 2006 for more detail). A particularly important finding of the study was that HAEC exposure to oxidised lipids results in the induction of the unfolded protein response (UPR), which directly participates in modulating inflammatory response. UPR, and more specifically the activating transcription factor 4 (ATF4), was an important mediator of IL-8 expression in HAEC. Recent studies have demonstrated that HDL treatment of HAEC downregulates the inflammatory and pro-oxidant effects of ox-PAPC. HDL has a protective role in regulating ox-PAPC signalling by reducing the induction of chemotactic, sterol biosynthetic and UPR genes, and reducing oxPAPC-induced chemotactic activity and monocyte binding regulated by IL-8 and monocyte chemotactic protein 1 (MCP-1) (Gharavi et al., 2007).

Proteomic studies have been proved to be a useful tool with which to understand the extensive mechanisms underlying atherosclerosis. Kinumi et al. (2005) showed that oxLDL-stimulated HUVEC resulted in the suppression of cell proliferation, which was ascribed to protein modifications, such as phosphorylation and autodegradation, and/or altered expression of nucleophosmin, stathmin, and nucleolin under these oxidative stress conditions. Furthermore, different forms of oxidatively modified LDL regulated HUVEC protein expression in different patterns (Chen et al., 2007), LDL isolated from familial hypercholesterolemia subjects (FHLDL) expressed approximately 3-fold higher concentration of MCP-1 than did cells subject to copper-oxidized LDL and atheroma-derived LDL (aLDL). The expression of heterogeneous nuclear ribonucleoprotein (hnRNP) C1/C2 was enhanced by FH-LDL and a-LDL, while glutation transferase was enhanced only by FH-LDL. This study suggests different roles for different oxLDL forms in inducing atherosclerosis.

\subsection{Effect of lipoproteins on regulation of gene and protein expression in vascular smooth muscle cells}

OxLDL induce a wide range of biological effects on SMC. The response of cultured SMC depends on the degree of oxidation and the extracellular concentration of oxLDL (Kita et al., 2001). Global analysis of gene expression profiling in oxLDL treated aortic SMC (HASMC), demonstrated that oxLDL predominantly elevates expression of genes involved in cell-cell interactions, membrane transport, oncogenesis, apoptosis and transcription as well as down regulation of genes responsible for protein, nuclei acid biosynthesis, lipid metabolism and humoral responses. Two transcripts for metastasisrelated protein (MB2) and scavenger receptor SRECII were firstly identified in vascular SMC (Sukhanov et al., 2003). To evaluate the global effects of oxLDL on cellular groups of proteins and to compared protein microarray data with the cDNA microarray-base gene expression results, Sukhanov and Delafontaine (2005) used protein chip-based microarray technology. This technique is based on highly specific interactions between a set of nonlabeled antibodies spotted on the activated side (biochip) and a mix of labelled antibodies taken from experimental and control sample (probe). Results revealed the major pattern of oxLDL-induced effects on HASMC functions, proteins involved in cell-cell interaction were predominantly up-regulated by ox-LDL (cadherin-3, cadhrin-5 and integrin 35 ), whereas those involved in nucleic acid and protein biosynthesis (tRNA-synthetases, phosphoribosyltransferase, deoxyxytidine kinase) and in cellular structure and humoral response were underexpressed in oxLDLtreated HASMC.

OxLDL also differentially expressed genes involved in redox homeostasis, $\mathrm{Ca} 2+$ signalling, immune response and apoptosis in coronary artery SMC (Reeve et al., 2007). oxLDL induced the expression of glutathione reductase, $N A D(P) H$ dehydrogenase-1, calcium/calmodulin-dependent protein kinase kinase $2 \beta$ (CAMKK2 $\beta$ ), heat shock 
factor-1 (HSF-1) and reduced the mRNA levels of vascular endothelial growth factor $A$ (VEGFA) precursor and apoptosis inhibitor 5 (API5), among others. OxLDL induced an oxidative stress response in those cells, as indicated by additional promoted expression of manganese superoxide dismutase (MnSOD), hemoxygenase-1 (HO-1) and ferritine, which was not accompanied by activation of the unfolded protein response. The high levels of oxidative estress induced by oxLDL caused caspase-indepented coronary arteries SMC death.

Padró et al. (2008) have recently identified using a quantitative proteomic approach (twodimensional gel electrophoresis coupled with mass spectrometry) that native and aggregated LDL induce significant changes in proteins directly involved in the assembly/disassembly and stabilization of human coronary SMC (HCSMC) cytoskeleton network. LDL both in their native form or modified by aggregation, alter the expression and proteomic pattern of different isoforms of myosin regulatory light chain, which regulation of phosphorilation is proposed to play an important role in controlling morphological changes during cell attachment, spreading and migration.

\subsection{Effect of lipoproteins on regulation of gene and protein expression in macrophages}

Monocyte-derived macrophages play a crucial role in the pathogenesis of atherosclerosis. In the early stages of the atherosclerosis lesion (fatty streak), lipid-laden macrophages (foam cells) appear to be most prominent. Several studies have used a proteomic approach to identify the response to human monoblastic leukaemia (U937) cell line (Yu et al., 2003, Yang et al., 2007), THP-1 cells (Fach et al., 2004) and human monocyte-derived macrophages (Dupont et al., 2008) after treatment with oxLDL. Among the intracellular and secreted proteins that were found to be modulated by oxLDL, several were involved in atherosclerosis including heat shock proteins (HSP), proteins involved in oxidative stress (catalase, aconitase and pyruvate kinase) and proteins involved in cytoskeletal stabilization, such as F-actin capping proteins involved in Actin polymerization and motility (gelsolin, CapG and CapZ) and vimentin.

OxLDL have been suggested to modulate gene expression in THP-1. Changes in genes that code for potent intracellular and extracellular signalling molecules such as the nuclear factor kappa-b (NFkB), A20 and numerous cytokines (interleukin 1beta, IL-1 $\beta$ and tumor necrosis factor-alpha, TNF- $\alpha$ ) and chemokines (macrophage inflammatory protein 1-alpha, Mip-1 $\alpha$; Mip-3 $\alpha$; Mip-1 $\beta$ and IL-8) were detected. Furthermore, some of the effects appear to be mediated through altered regulation of NF-kB signalling and activation of the nuclear receptors retinoid $X$ receptor ( $R X R)$ and peroxisomal proliferators activated receptor (PPAR) $\gamma$ (Mikita et a., 2001). Levula et al. (2006), investigated the changes in gene expression induced by oxLDL and oxHDL in healthy human macrophages. Both lipoproteins seemed to have different, even contrasting, effects on the gene expression of macrophage derived foam cells, probably due to their different composition or possibly they use different scavenger receptor to enter these cells. They suggested new candidate genes for foam cell formation such as those involved in lipid metabolism (fatty acid binding protein 3, FABP3; LDL-receptor protein 1; LRPAP1 and very long chainacyl-coA dehydrogenase, VLCAD); and in inflammation, growth and haemostasis (small inducible cytokine A1, SCYA1; vascular endothelial growth factor 165 receptor 2, VEGF165R2; and thrombospondin 2, THBS2).

Recent reported findings indicate that there is an important immunological and inflammatory aspect of atherosclerosis. Several autoimmune diseases are associated with accelerated atherosclerosis, increased plasma levels of circulating oxLDL, antioxLDL antibodies, dyslipidemia and enhance inflammation (Frostegård, 2005). OxLDL is immunogenic and elicits the production of antibodies, predominantly of the pro-inflammatory IgG1 and IgG3 isotypes (Saad et al., 2006). Antibodies from circulating immune complexes containing oxLDL (oxLDL-IC) activate both cell-mediated and humoral immune responses, both responses are pro-inflammatory and play an important role in the perpetuation of the chronic inflammatory reaction characteristic of atherosclerosis. Recently, gene expression changes induced by oxLDL-IC have been investigated in the human monocytic cell line U937 (Hammad et al., 2008). These studies have shown early transcriptional responses elicited by oxLDL-IC that may underlie its cytoprotective and proinflammatory effects compared to oxLDL. OxLDL-IC uniquely affected the expression of genes involved; with pro-survival (RAD54B; run and five domains-containing protein 3, RUFY3; small nuclear ribonucleoprotein polypeptide b-double prime, SNRPB2 and ZBTB24); with stress response, including UPR which impacts cell survival; with regulation of transcription; with endocytosis and intracellular transport of protein and lipid; with inflammatory responses including regulation of I-kB/NF-kB cascade and with cytokine activity. Cross-linking of $\mathrm{Fc} \gamma$ receptors appears to be the trigger for most of the transcriptional responses to oxLDL-IC.

\section{NOVEL ATHEROGENIC MECHANISMS INVOLVED IN POSTPRANDIAL TRL: MOLECULAR MECHANISMS AND GENE EXPRESSION STUDIES}

Overproduction of TRL, characteristic of postprandial lipemia leads to a complex series of events potentially inducing atherogenesis, however, 
the mechanisms by which TRL exert their effect on the vascular wall are largely unknown.

\subsection{Postprandial lipoproteins and endothelial dysfunction}

Remnant like-lipoproteins have been associated with endothelial dysfunction and coronary artery disease in subjects with metabolic syndrome (Nakamura et al., 2005). A large number of genes are regulated after exposure of endothelial cells to $T R L$ with the net effect reflecting receptor and nonreceptor mediated pathways that are activated or inhibited depending on the fatty acid type, lipid and apolipoprotein composition of TRL and the presence or absence of lipoprotein lipase (Williams et al., 2004). TRL have been shown to induce pro- and anti-inflammatory responses in the endothelium, the composition of TRL has been shown to play a key role in determining these responses. In that sense, TRL isolated after a meal enriched in saturated fatty acids induced E-selectin, vascular cell adhesion molecule 1 (VCAM1) and lectin-like oxidised-LDL receptor 1 (LOX1) gene expression to a higher extent when compared to TRL isolated after a meal enriched in mono and poly-saturated fatty acids (Williams et al., 2004); similarly, chylomicrons separated after ingestion of safflower oil, rich in polyunsaturated linoleic acid, induced higher adhesion molecule expression compared with chylomicrons separated after ingestion of olive oil, rich in monounsaturated oleic acid (Jagla and Schrezenmeir, 2001). Effects of lipoproteins on vasoactive substances seem to be implicated in endothelial dysfunction too. The endothelium-derived relaxing factor nitric oxide (NO) has gained increasingly attention as is regarded as protective against hypertension and atherosclerosis. In general, high-fat meals have often been associated with a loss of postprandial vascular reactivity compared to low fat meals. However several studies have shown that differences in food components and fatty acid content of the meals may contribute to the effects observed on vascular reactivity by means of postprandial lipoproteins modifications. Thus, meals containing monounsaturated fatty acids + eicosapentaenoic/docosahexaenoic acids (EPA/DHA) are able to attenuate the impairment of endothelial function probably by reducing the most atherogenic postprandial lipoprotein subclass containing apolipoproteins $B$ and C (Hilpert et al., 2007); likewise, consumption of a saturated fat reduces the anti-inflammatory potential of postprandial HDL and impairs arterial endothelial function, meanwhile, the antiinflammatory activity of HDL improves after consumption of polyunsaturated fat (Nicholls et al., 2006). TRL composition may also contribute to the changes observed in vascular dysfunction, thus, TRL isolated after a fish oil meal improves vascular reactivity, increasing endothelial nitric oxide synthase (eNOS) and decreasing NADP oxidase gene expression (Armah et al., 2008).

Postprandial TRL from hypertrigliceridemic patients but not by normolipidemic subjects induced a large set of pro-inflammatory (VCAM-1; endothelial leukocyte adhesion molecule 1, ELAM1; platelet-endothelial cell adhesion molecule 1, PECAM1 and IL6) and pro-thrombotic (plasminogen activator inhibitor 1, PAl-1; a disintegrin-like and metalloproteinase with thrombospondin type1, ADAMTs1) genes in endothelial cells. Furthermore, TRLs induced MCP-1 expression suggesting that the activation of the endothelium could support both adhesion and transmigration of leukocytes (Norata et al., 2006). As the induction of adhesion molecules and release of chemokines have been associated with endothelial dysfunction, it can be proposed that endothelial activation by TRL may promote endothelial dysfunction observed after a meal. Activation of the extracellular-signal regulated kinase (ERK)1/2 and p38 mitogen-activated protein kinase (MAPK) pathways and of the transcription factors CAMP response element-binding protein (CREB); NF-kB and nuclear factor of activated T cells (NFAT) (Norata et al., 2003; Norata el al., 2006, Norata et al., 2007) could be responsible for these effects. Recently, it has been shown that, postprandial hypertriglyceridemia is a leukocyte activator most likely by direct interaction between TRL and leukocytes and uptake of meal-derived fatty acids (Alipour et al., 2008). Therefore, binding of TRL to the leukocytes, may be one of the first steps in the process of atherosclerosis in contrast to the present view that it starts by migration of LDL and TRL-remnants to the sub-endothelium. These findings highlight novel mechanisms by which postprandial lipoproteins may influence key atherogenic processes.

\subsection{Effect of postprandial lipoproteins on subendothelial cells}

TRL can penetrate the vessel wall (Rapp et al., 1994) they are taken up by macrophages and smooth muscle cells and are detectable as part of foam cells in vascular lesions (Bravo and Napolitano, 2007). This may support a potential role of TRL in the subendothelial space. The direct effects of remnant lipoproteins on SMC and macrophages and the mechanisms involved have been reviewed by Kawakami and Yoshida (2005).

Vascular smooth muscle cells migration and subsequent proliferation from media to intima play key roles in atherogenesis. Remnant TRLs have been shown to induce the proliferation (Kawakami et al., 2003) and migration (Aramaki et al., 2008) of SMCs via activation of MAPK, in which G protein-coupled receptor (GPCR)-dependent or independent protein kinase $C$ (PKC) activation followed by epidermal growth factor receptor (EGF) transactivation and heparing-binding EGF-like growth factor shedding were shown to be involved. 
Aramaki et al. (2008) also showed that LOX-1 acts as a receptor for remnant TRL in SMC.

The composition of TRL needs to be taken into account when discussing the effects of TRL on vascular proliferation (Pacheco et al., 2002). In that sense, recent cDNA microarray studies (Bermudez et al., 2008) have shown that isolated human TRL enriched in monounsaturated (TRL-refined olive oil; TRL-ROO), saturated (TRL-BUTTER) and polyunsaturated fatty acids (TRL-vegetable and fish oil; TRL-VEFO), can provoke differential gene expression in human coronary artery smooth muscle cells. TRL-BUTTER predominantly activated genes involved in the regulation of cell proliferation (cyclin D1, CCND1; Cyclin E1, CCNE1; retinoblastoma 1, RB1; proliferatinf cells nuclear antigen, PCNA) and inflammation (IL8; cyclooxygenase 2, COX2), TRL-VEFO induced the expression of genes implicated in inflammation (IL8, IL1B, MCP-1) while TRL-ROO promoted a less atherogenic gene profile which could improve atherosclerotic-plaque stability and support the prescription of olive oil-enriched diets in secondary prevention of cardiovascular disease.

\section{CONCLUSION}

This review summarises recent data that support the use of "omics" technologies to identify, in vitro and in vivo studies, a tractable set of new genes and protein biomarkers candidates of atherosclerosis that may eventually be developed to measure the extent, progression, regression and stability of atherosclerotic lesions provoked by the diet. While these biomarkers will hopefully develop into indicative and predictive set of molecules, their diagnostic power can not be uncoupled from predetermined genetic disposition.

The insights gained from the studies of postprandial lipoproteins may reinforce the fundamental link between dietary factors and the aetiology of atherosclerosis. These observations also suggest that TRL contribute to atherogenesis by directly affecting the vascular cells. Therefore, future efforts to study and treat lipids related to atherogenesis should include postprandial parameters. Based on the nutrigenomic approache, we can suggest that the pathophysiological contribution of postprandial TRL to the development of atherosclerosis and the stability of the atherosclerotic plaque could, in part, depend on the fatty acid composition of $T R L$, indicating that the quality of the plaque rather than the quantity may determine the clinical consequences of atherosclerosis.

Further studies are needed to help to discern whether the effects of lipoproteins in the fasting and postprandial state on the genes and proteins investigated in these studies are relevant under human physiological conditions. This is not an easy task, since one major cause for the lack of nutritionally relevant investigations in humans is the constraint of being non-invasive when it comes to sampling for nutritional studies.

\section{ACKNOWLEDGEMENTS}

This work has been partially supported by grant (AGL2005-03722) from the Spanish Ministry of Innovation and Science.

\section{REFERENCES}

Abia R, Pacheco YM, Perona JS, Montero E, Muriana FJ, Ruiz-Gutiérrez V. 2001. The metabolic availability of dietary triacylglycerols from two high oleic oils during the postprandial period does not depend on the amount of oleic acid ingested by healthy men. $J$ Nutr. 131, 59-65.

Alipour A, van Oostrom AJ, Izraeljan A, Verseyden C, Collins JM, Frayn KN, Plokker TW, Elte JW, Castro Cabezas M. 2008. Leukocyte activation by triglyceride-rich lipoproteins. Arterioscler. Thromb. Vasc. Biol. 28, 792-797.

Arab L. 2004. Individualized nutritional recommendations: do we have the measurements needed to assess risk and make dietary recommendations? Proc. Nutr. Soc. 63, 167-172.

Aramaki Y, Mitsuoka H, Toyohara M, Jinnai T, Kanatani K, Nakajima K, Mukai E, Yamada Y, Kita T, Inagaki N, Kume N. 2008. Lectin-like oxidized LDL receptor-1 (LOX-1) acts as a receptor for remnant-like lipoprotein particles (RLPs) and mediates RLP-induced migration of vascular smooth muscle cells. Atherosclerosis 198, 272-279.

Armah CK, Jackson KG, Doman I, James L, Cheghani F, Minihane AM. 2008. Fish oil fatty acids improve postprandial vascular reactivity in healthy men. Clin. Sci. (Lond), 114, 679-686.

Bansal S, Buring JE, Rifai N, Mora S, Sacks FM, Ridker PM. 2007. Fasting compared with nonfasting triglycerides and risk of cardiovascular events in women. JAMA 298, 309-316.

Bermúdez B, López S, Pacheco YM, Villar J, Muriana FJ, Hoheisel JD, Bauer A, Abia R. 2008. Influence of postprandial triglyceride-rich lipoproteins on lipidmediated gene expression in smooth muscle cells of the human coronary artery. Cardiovasc. Res. 79, 294303.

Berliner JA, Subbanagounder G, Leitinger N, Watson AD, Vora D. 2001. Evidence for a role of phospholipid oxidation products in atherogenesis. Trends Cardiovasc. Med. 11, 142-147.

Bravo E, Napolitano M. 2007. Mechanisms involved in chylomicron remnant lipid uptake by macrophages. Biochem. Soc. Trans 35, 459-463.

Chen CY, Lee CM, Hsu HC, Yang CY, Chow LP, Lee YT. 2007. Proteomic approach to study the effects of various oxidatively modified low-density lipoprotein on regulation of protein expression in human umbilical vein endothelial cell. Life Sci. 80, 2469-2480.

Cohn JS. 2006. Postprandial lipemia and remnant lipoproteins. Clin. Lab. Med. 26, 773-786.

Dupont A, Chwastyniak M, Beseme O, Guihot AL, Drobecq H, Amouyel P, Pinet F. 2008. Application of saturation dye 2D-DIGE proteomics to characterize proteins modulated by oxidized low density lipoprotein 
treatment of human macrophages. J. Proteome Res. 7, 3572-3582.

Fach EM, Garulacan LA, Gao J, Xiao Q, Storm SM, Dubaquie YP, Hefta SA, Opiteck GJ. 2004. In vitro biomarker discovery for atherosclerosis by proteomics. Mol. Cell. Proteomics 3, 1200-1210.

Fitó M, Guxens M, Corella D, Sáez G, Estruch R, de la Torre R, Francés F, Cabezas C, López-Sabater Mdel C, Marrugat J, García-Arellano A, Arós F, RuizGutierrez V, Ros E, Salas-Salvadó J, Fiol M, Solá R, Covas Ml; for the PREDIMED Study Investigators. 2007. Effect of a traditional Mediterranean diet on lipoprotein oxidation: a randomized controlled trial. Arch. Intern. Med. 167, 1195-1203.

Frostegård J. 2005. Atherosclerosis in patients with autoimmune disorders. Arterioscler. Thromb. Vasc. Biol. 25, 1776-1785.

Furtado JD, Campos H, Appel LJ, Miller ER, Laranjo N, Carey VJ, Sacks FM. 2008. Effect of protein, unsaturated fat, and carbohydrate intakes on plasma apolipoprotein B and VLDL and LDL containing apolipoprotein C-III: results from the OmniHeart Trial. Am. J. Clin. Nutr. 87, 1623-1630.

Galle J, Hansen-Hagge T, Wanner C, Seibold S. 2006. Impact of oxidized low density lipoprotein on vascular cells. Atherosclerosis 185, 219-226.

Gargalovic PS, Imura M, Zhang B, Gharavi NM, Clark MJ, Pagnon J, Yang WP, He A, Truong A, Patel S, Nelson SF, Horvath S, Berliner JA, Kirchgessner TG, Lusis AJ. 2006. Identification of inflammatory gene modules based on variations of human endothelial cell responses to oxidized lipids. Proc. Natl. Acad. Sci. U S A 103, 12741-12746.

Gharavi NM, Gargalovic PS, Chang I, Araujo JA, Clark MJ, Szeto WL, Watson AD, Lusis AJ, Berliner JA. 2007. High-density lipoprotein modulates oxidized phospholipid signaling in human endothelial cells from proinflammatory to anti-inflammatory. Arterioscler. Thromb. Vasc. Biol. 27, 1346-53.

Hammad SM, Twal WO, Barth JL, Smith KJ, Saad AF, Virella G, Scott Argraves W, Lopes-Virella MF. 2008. Oxidized LDL immune complexes and oxidized LDL differentially affect the expression of genes involved with inflammation and survival in human U937 monocytic cells. Atherosclerosis (Epub ahead of print)

Hilpert KF, West SG, Kris-Etherton PM, Hecker KD, Simpson NM, Alaupovic P. 2007. Postprandial effect of n-3 polyunsaturated fatty acids on apolipoprotein Bcontaining lipoproteins and vascular reactivity in type 2 diabetes. Am. J. Clin. Nutr. 85, 369-376.

Hurtado I, Fiol C, Gracia V, Caldú P. 1996. In vitro oxidised HDL exerts a cytotoxic effect on macrophages. Atherosclerosis 125, 39-46.

Jagla A, Schrezenmeir J. 2001. Postprandial triglycerides and endothelial function. Exp. Clin. Endocrinol. Diabetes 109, S533-547.

Kawakami A, Tanaka A, Chiba T, Nakajima K, Shimokado K, Yoshida M. 2003. Remnant lipoprotein-induced smooth muscle cell proliferation involves epidermal growth factor receptor transactivation. Circulation 108, 2679-2688.

Kawakami A, Yoshida M. 2005. Remnant lipoproteins and atherogenesis. J. Atheroscler. Thromb. 12, 73-76.

Kinumi T, Ogawa Y, Kimata J, Saito Y, Yoshida Y, Niki E. 2005. Proteomic characterization of oxidative dysfunction in human umbilical vein endothelial cells (HUVEC) induced by exposure to oxidized LDL. Free Radic. Res. 39, 1335-1344.
Kita T, Kume N, Minami M, Hayashida K, Murayama T, Sano $\mathrm{H}$, Moriwaki $\mathrm{H}$, Kataoka $\mathrm{H}$, Nishi E, Horiuchi $\mathrm{H}$, Arai H, Yokode M. 2001. Role of oxidized LDL in atherosclerosis. Ann. N. Y. Acad. Sci. 947, 199-205.

Lopez-Miranda J, Williams C, Lairon D. 2007. Dietary, physiological, genetic and pathological influences on postprandial lipid metabolism. Br. J. Nutr. 98,458-473.

Levula M, Jaakkola O, Luomala M, Nikkari ST, Lehtimäki T. 2006. Effects of oxidized low- and high-density lipoproteins on gene expression of human macrophages. Scand. J. Clin. Lab. Invest. 66, 497508.

Mikita T, Porter G, Lawn RM, Shiffman D. 2001. Oxidized low density lipoprotein exposure alters the transcriptional response of macrophages to inflammatory stimulus. J. Biol. Chem. 276, 45729-45739.

Mora S, Rifai N, Buring JE, Ridker PM. 2008. Fasting compared with nonfasting lipids and apolipoproteins for predicting incident cardiovascular events. Circulation 118, 993-1001.

Nakamura T, Takano H, Umetani K, Kawabata K, Obata JE, Kitta Y, Kodama Y, Mende A, Ichigi Y, Fujioka D, Saito Y, Kugiyama K. 2005. Remnant lipoproteinemia is a risk factor for endothelial vasomotor dysfunction and coronary artery disease in metabolic syndrome. Atherosclerosis 181, 321-327.

Nicholls SJ, Lundman P, Harmer JA, Cutri B, Griffiths KA, Rye KA, Barter PJ, Celermajer DS. 2006. Consumption of saturated fat impairs the antiinflammatory properties of high-density lipoproteins and endothelial function. J. Am. Coll. Cardiol. 48, 715720.

Nordestgaard BG, Benn M, Schnohr P, Tybjaerg-Hansen A. 2007. Nonfasting triglycerides and risk of myocardial infarction, ischemic heart disease, and death in men and women. JAMA 298, 299-308.

Norata GD, Grigore L, Raselli S, Redaelli L, Hamsten A, Maggi F, Eriksson P, Catapano AL. 2007. Post-prandial endothelial dysfunction in hypertriglyceridemic subjects: molecular mechanisms and gene expression studies. Atherosclerosis 193, 321-327.

Norata GD, Grigore L, Raselli S, Seccomandi PM, Hamsten A, Maggi FM, Eriksson P, Catapano AL. 2006. Triglyceride-rich lipoproteins from hypertriglyceridemic subjects induce a pro-inflammatory response in the endothelium: Molecular mechanisms and gene expression studies. J. Mol. Cell. Cardiol. 40, 484-494.

Norata GD, Pirillo A, Callegari E, Hamsten A, Catapano AL, Eriksson P. 2003. Gene expression and intracellular pathways involved in endothelial dysfunction induced by VLDL and oxidised VLDL. Cardiovasc. Res. 59, 169-180.

Pacheco YM, Abia R, Perona JS, Meier KE, Montero E, Ruiz-Gutiérrez V, Muriana FJ. 2002. Triacylglycerolrich lipoproteins trigger the phosphorylation of extracellular-signal regulated kinases in vascular cells. Life Sci. 71, 1351-1360.

Padró T, Peña E, García-Arguinzonis M, Llorente-Cortes V, Badimon L. 2008. Low-density lipoproteins impair migration of human coronary vascular smooth muscle cells and induce changes in the proteomic profile of myosin light chain. Cardiovasc. Res. 77, 211-220.

Rapp JH, Lespine A, Hamilton RL, Colyvas N, Chaumeton AH, Tweedie-Hardman J, Kotite L, Kunitake ST, Havel RJ, Kane JP. 1994. Triglyceriderich lipoproteins isolated by selected-affinity antiapolipoprotein B immunosorption from human atherosclerotic plaque. Arterioscler. Thromb. 14, 1767-1774. 
Reeve JL, Stenson-Cox C, O'Doherty A, Pörn-Ares I, Ares M, O'Brien T, Samali A. 2007. OxLDL-induced gene expression patterns in CASMC are mimicked in apoE-/- mice aortas. Biochem. Biophys. Res. Commun. 356, 681-686.

Saad AF, Virella G, Chassereau C, Boackle RJ, LopesVirella MF. 2006. OxLDL immune complexes activate complement and induce cytokine production by MonoMac 6 cells and human macrophages. J. Lipid. Res. 47, 1975-1983.

Subbiah MT. 2008. Understanding the nutrigenomic definitions and concepts at the food-genome junction. OMICS 12, (Epub ahead of print)

Sukhanov S, Delafontaine P. 2005. Protein chip-based microarray profiling of oxidized low density lipoprotein-treated cells. Proteomics 5, 1274-1280.

Sukhanov S, Hua Song Y, Delafontaine P. 2003. Global analysis of differentially expressed genes in oxidized LDL-treated human aortic smooth muscle cells. Biochem. Biophys. Res. Commun. 306, 443-449.

Tall AR. 2008. Cholesterol efflux pathways and other potential mechanisms involved in the atheroprotective effect of high density lipoproteins. J. Intern. Med. 263, 256-273.

Thompson SM, Arrowsmith FE, Allen JR. 2003. Dietary management of galactosemia. Southeast Asian J. Trop. Med. Public. Health 34, 212-214.

Tsimikas S, Brilakis ES, Miller ER, McConnell JP, Lennon RJ, Kornman KS, Witztum JL, Berger PB. 2005. Oxidized phospholipids, Lp(a) lipoprotein, and coronary artery disease. N. Engl. J. Med. 353, 46-57.

Tsimikas S, Kiechl S, Willeit J, Mayr M, Miller ER, Kronenberg F, Xu Q, Bergmark C, Weger S,
Oberhollenzer F, Witztum JL. 2006. Oxidised phospholipids predict the presence and progression of carotid and femoral atherosclerosis and symptomatic cardiovascular disease: five-year prospective results from the Bruneck study. J. Am. Col. Cardiol. 47, 2219-2228.

Valiyaveettil M, Kar N, Ashraf MZ, Byzova TV, Febbraio M, Podrez EA. 2008. Oxidized high-density lipoprotein inhibits platelet activation and aggregation via scavenger receptor BI. Blood 111, 1962-1971.

van Spronsen FJ, van Rijn M, Bekhof J, Koch R, Smit PG. 2001. Phenylketonuria: tyrosine supplementation in phenylalanine-restricted diets. Am. J. Clin. Nutr. 73, 153-157.

Virgili F, Ambra R, Muratori F, Natella F, Majewicz J, Minihane AM, Rimbach G. 2003. Effect of oxidized low-density lipoprotein on differential gene expression in primary human endothelial cells. Antioxid. Redox Signal 5, 237-247.

Williams CM, Maitin V, Jackson KG. 2004. Triacylglycerolrich lipoprotein-gene interactions in endothelial cells. Biochem. Soc. Trans 32, 994-998.

Yang PY, Rui YC, Yang PY, Yu YL. 2007. Proteomic analysis of foam cells. Methods Mol. Biol. 357, 297305.

Yu YL, Huang ZY, Yang PY, Rui YC, Yang PY. 2003. Proteomic studies of macrophage-derived foam cell from human U937 cell line using two-dimensional gel electrophoresis and tandem mass spectrometry. J. Cardiovasc. Pharmacol. 42, 782-789.

Recibido: 4/8/08 Aceptado: 1/9/08 